\title{
A estrutura fatorial dos atributos valorativos e descritivos do trabalho: um estudo empírico de aperfeiçoamento e validação de um questionário.
}

Livia de Oliveira Borges

Universidade Federal do Rio Grande do Norte

Resumo

O estudo objetivou aprofundar a compreensão da estrutura fatorial dos atributos valorativos (o que deve ser) e descritivos (o que é) do trabalho e aperfeiçoar o instrumento de medida destas facetas do significado do trabalho. Foi desenvolvido com 622 trabalhadores de uma construtora habitacional e duas redes de supermercado, no Distrito Federal, através da aplicação do Inventário do Significado do Trabalho (IST) e de entrevistas. Os resultados consistem em duas estruturas fatoriais distintas para os atributos valorativos e descritivos. A primeira, com cinco fatores, "Exigências Sociais", "Justiça no Trabalho", "Esforço Corporal e Desumanização", "Realização Pessoal" e "Sobrevivência Pessoal e Familiar". A segunda, com quatro fatores, "Êxito e Realização Pessoal", "Justiça no Trabalho", "Sobrevivência Pessoal e Familiar" e "Carga Mental'. As análises fatoriais secundárias apontaram que a principal idéia aglutinadora, entre os atributos valorativos, é a função social do trabalho, enquanto entre os atributos descritivos é a dureza do trabalho.

Palavras-chave: Significado do trabalho, Valores do trabalho, Percepção do trabalho, Mensuração, Medida. 


\begin{abstract}
The factor structure of descriptive and value attributes of work: an empirical study of validation and improvement of a questionnaire

The study aims at improving the comprehension of the factor structure of value (what it must be) and descriptive (what it is) attributes of work, and the betterment of the measuring instrument of these facets of the meaning of work. It was de developed with 622 workers, in a dwelling building firm and two supermarket chains in the Federal District of Brazil. These workers took part in the study, submitted to the application of the Work Meaning Inventory and interviews. The results consist of two distinct factor structures of the attributes of values and description. The first with five factors: "Social Exigencies", "Work Justice", "Physical Effort and No-Humanization", "Personal Realization", and "Familiar and Personal Survival'. The second, with four factors: "Success and Personal Realization", "Work Justice", "FaKey words: miliar and Personal Survival", and "Mental Load". Second Work meaning, order factor analysis has shown that the main idea, which Work values, agglutinates the values attributes, is the social function of
ork perception, Measurement,
work, while among the description attributes is the hardness
\end{abstract} Measure. of work.

partir de meados da década de 80, no campo da Psicologia
Organizacional e do Trabalho, vem consolidando-se uma
linha de pesquisa sobre o significado do trabalho. A publi- 
No Brasil, estudos seguindo a abordagem e a metodologia daquela equipe encontraram dificuldade em comprovar os aspectos sócionormativos como uma faceta distinta (Soares, 1992; Borges-Andrade, Martins \& Abbad-OC, 1995; Borges-Andrade \& Nogueira, 1994).

Divergências também se multiplicaram neste campo de estudos. Assim, Brief e Nord (1990) e demais autores da coletânea por eles coordenada chamaram a atenção para a necessidade de ampliar o leque dos valores do trabalho e de incorporação de atributos negativos. Certamente, sintonizada com esta perspectiva, Sato (1993 e 1995), através do desenvolvimento de estudo empírico com motoristas de ônibus, no Rio de Janeiro, analisou a atribuição do significado de penosidade.

Muitos autores (por exemplo, Kohn \& Schooler, 1983; Jahoda, 1987; Codo, 1984, 1993; Codo, Sampaio, Hitomi \& Bauer, 1995; Locke \& Taylor, 1990) têm chamado atenção para o papel estruturante do trabalho no processo contínuo de desenvolvimento da personalidade e/ou da identidade. Pérez (1996) destaca o caráter positivo dos significados atribuídos ao trabalho encontrado em seus estudos.

Outros autores, tais como Codo (1984), Katzell (1994) e MartinBaró (1990) têm criticado os estudos na Psicologia, por negligenciarem em considerar a associação do trabalho às condições históricas da sociedade.

Tamayo (1994) e Borges (1996) sublinham a atribuição do significado de garantia da sobrevivência no Brasil como distinta do significado econômico atribuído pelas pessoas nos países desenvolvidos.

Martin-Baró (1990) e Aktouf (1986) desenvolveram estudos empíricos elucidando a associação dialética do trabalho tanto ao sofrimento como à alegria, sendo que o primeiro autor assim o faz articulando o uso de métodos quantitativos e qualitativos.

Ros, Schwartz e Surkiss (1999), fundamentando-se na Teoria dos Valores Individuais Básicos, desenvolveram a crítica aos estudos sobre os valores do trabalho, apontando a negligência em destacar um tipo de valor referente a poder, prestígio e influência, e mostrando que a consideração destes valores ocorre nos estudos incluindo-os entre valores expressivos, o que consideram insuficiente. Desenvolveram estudo empírico confirmando a pertinência da crítica. 
Esclarece-se que a Teoria dos Valores Individuais Básicos propõe (Schwartz \& Bilsky, 1990; Tamayo \& Schwartz, 1993; Schwartz, 1994) uma classificação dos valores em dez tipos, a saber: autodeterminação (independência de pensamento e ação), universalismo ou filantropia (preocupação com o bem-estar de todos), benevolência (interesse e preocupação com o bem-estar de pessoas íntimas), autorealização (meta de sucesso e de demonstração de competência), hedonismo (prazer e gratificação pessoal), conformidade (controle pessoal de acordo com as expectativas sociais), tradição (respeito e aceitação dos ideais e costumes da sua sociedade), estimulação (busca de excitação e mudança), segurança (estabilidade da sociedade e de si mesmo) e poder (busca de status social, prestígio e controle).

O conjunto destes dez tipos, por sua vez, apresenta uma estrutura circular baseada em relações de oposições e adjacências conforme duas dimensões bipolares - "conservação" versus "abertura" e "autotranscedência" versus "autopromoção" — as quais seriam responsáveis pelo dinamismo entre valores humanos.

Tem chamado a atenção da autora deste artigo o fato de os estudos no Brasil que utilizam questionários estruturados reproduzirem as limitações de valores contidos no estudo da equipe do MOW, problema que se agrava por não contemplar as peculiaridades da brasilidade (Borges, 1997 e 1998), bem como a omissão dos estudos na Psicologia em considerar atributos, tais como exploração, hominização ${ }^{2}$, embrutecimento e alienação, os quais encontram amparo teórico no marxismo.

Esclarece-se que o termo atributo foi utilizado na bibliografia sobre o significado do trabalho por Salmaso e Pombeni (1986), porém estes estudiosos não faziam a diferenciação entre atributos valorativos e descritivos como proposto pela autora do presente artigo.

Seguindo a compreensão do significado do trabalho como multifacetado, a autora em estudo anterior (Borges, 1997 e 1998) propôs a distinção entre atributos valorativos e descritivos, enquanto facetas diversas, e o Inventário do Significado do Trabalho como instrumento de medida destas. Os atributos valorativos consistem em uma definição do que "deve ser" o trabalho. São, portanto, os valores do traba- 
lho. Os atributos descritivos referem-se, então, à percepção do trabalho concreto, ou seja, caracterizam o trabalho como ele é.

O referido inventário, por sua vez, foi composto de 58 itens consistindo em frases que representavam 29 tipos de atributos levantados através de estudo empírico anterior (Borges, 1996), com amostra de trabalhadores da construção civil, confecções e costura e comércio, no Distrito Federal. Encontrou-se uma estrutura fatorial para cada faceta (atributos valorativos e descritivos). Foram identificados quatro fatores entre os Atributos Valorativos (Escala Verde - EV): "Independência Financeira e Prazer", "Justiça no Trabalho", "Esforço Físico e Aprendizagem" e "Dignidade Social", os quais, respectivamente, explicam 55,9\%, 25,7\%, 10,9\% e 7,5\% da variância compartilhada e todos apresentam coeficientes "alfa" a partir de 0,80 .

Entre os Atributos Descritivos (Escala Azul - EA), numa análise fatorial gerando quatro fatores, há apenas dois fatores consistentes $\left(\mathrm{a}^{3} 0,80\right)$, designados de "Expressão e Independência Financeira", "Execução e Função Social", os quais, respectivamente, explicam $58,8 \%$ e $9,7 \%$ da variância compartilhada e apresentam coeficiente Alfa de 0,88 e 0,81 . São o primeiro e quarto fatores da estrutura. O segundo fator, explicando $19,0 \%$ da variância compartilha$\mathrm{da}$, apresenta um coeficiente $\mathrm{a}=0,75$, permitindo considerá-lo promissor. Foi designado de "Respeito". O terceiro fator reunia apenas três itens e apresentava um coeficiente Alfa de apenas 0,43. Portanto, era inconsistente.

Tais resultados, à medida em que revelam duas estruturais fatoriais distintas, apontam a pertinência da distinção entre Atributos Valorativos e Descritivos. As duas escalas, porém, não apresentam a mesma consistência. Apesar de as frases utilizadas no IST se basearem em entrevistas com trabalhadores da construção civil, comércio e confecções e costura (Borges, 1996), não se sabia se a diferença de consistência das duas escalas refletia uma característica empírica ou problemas do instrumento de medida. A comparação das duas escalas conduziu à identificação de problemas em itens referentes à exploração, à assistência social (benefícios), ao conforto, ao reconhecimento, à discriminação, ao ritmo e à carga de trabalho, à saúde e à hominização. 
Planejou-se o presente estudo, objetivando promover o aperfeiçoamento do "Inventário do Significado do Trabalho" (IST) e aprofundar a compreensão da estrutura fatorial dos atributos valorativos e descritivos enquanto facetas do significado do trabalho.

\section{Método}

\section{Amostra}

Os dados foram coletados junto a 622 trabalhadores, dos quais $71,9 \%$ (447) de comerciários do setor de alimentação e de $28,1 \%$ (175) de trabalhadores da construção habitacional. Dos primeiros, 179 (28,8\% do total) eram empregados de uma rede pública de supermercados e 268 (43,1\% do total) de uma rede privada de supermercados.

Na construção da amostra, foram tomados cuidados no sentido de garantir a representatividade em relação ao quadro de pessoal de cada empresa, nas quais os dados foram coletados. Assim, os participantes da amostra estão distribuídos nas diversas instalações e setores de cada empresa como nos diversos cargos. Entretanto, não se dispõe de avaliação da representatividade em relação às categorias ocupacionais como um todo (trabalhadores da construção civil e trabalhadores do comércio de alimentos).

Testou-se a independência dos dados demográficos dos participantes da amostra e a categoria ocupacional, através da aplicação do teste Qui-quadrado. Há rejeição da independência da categoria ocupacional em relação ao nível de instrução $\left(c^{2}=166,15\right.$; para $r<$ 0,0001). Entre os trabalhadores da construção habitacional, a faixa de nível de instrução predominante $(54,2 \%)$ é ter estudado no máximo até a quarta série do $1^{\circ}$ grau, enquanto para os comerciários é ter estudos além do $1^{\circ}$ grau maior $(41,4 \%)$.

Há também quase que perfeita dependência entre o gênero dos participantes e a categoria ocupacional: $96 \%$ das mulheres são empregadas nas redes de supermercado e apenas $4 \%$ (9 participantes), na construtora habitacional, numa amostra composta de $63 \%$ de homens e $37,0 \%$ de mulheres. 


\section{Instrumentos de coleta de dados}

O principal instrumento de coleta de dados deste estudo é o IST (Inventário do Significado do Trabalho). Neste, foram acrescentados itens visando ao seu aperfeiçoamento. Passaram-se de 58 para 68 itens. Foram retirados aqueles que não apresentaram pesos acima de 0,30 nos fatores encontrados no estudo anterior e acrescidos novos itens referentes à "Igualdade/discriminação", "Exploração/Eqüidade", "Saúde", "Hominização", "Ritmo e Carga", "Reconhecimento e Conforto" e "Higiene".

Manteve-se sua forma básica de aplicação e de responder (Borges, 1997). Assim, para cada item, os participantes da amostra apresentam duas respostas: uma sobre a realidade (atributos descritivos) e outra sobre a definição de "deve ser" dos mesmos (atributos valorativos). As respostas consistem em designar de 0 a 4 pontos.

Criou-se, entretanto, uma versão adicional. A primeira, já existente (Borges, 1997), é aplicável a trabalhadores sem instrução formal ou que cursaram até a quarta série do $1^{\underline{0}}$ grau (equivalente ao antigo primário) e lança mão de recursos não-verbais. Assim, os participantes apresentam suas respostas utilizando cartões de duas cores básicas - verde e azul - uma para cada resposta, e com graduação de tonalidade em substituição aos pontos. A cor verde foi utilizada para as respostas correspondentes aos atributos valorativos e a cor azul, para as respostas correspondentes aos atributos descritivos. Deste modo, quanto mais escuro o tom do cartão verde escolhido pelo participante, mais o conteúdo da frase fala de algo que ele considera que "deve ser" ou que é certo. E quanto mais escura a tonalidade do cartão azul escolhido, mais a frase descreve a realidade ou o que "é".

A segunda versão, introduzida neste estudo, aplicável a partir do início do $1^{\underline{0}}$ grau maior, foi preparada para ser respondida com o uso do lápis pelo próprio participante. Considerando, contudo, que não se destina a um nível de instrução elevado e a adequação de primar pela semelhança à primeira versão, mesclou-se características verbais e não-verbais. Os participantes lêem as frases e respondem marcando círculos ou retângulos cheios. Os círculos substituem os cartões verdes e os retângulos, os cartões azuis. A graduação das 
escalas é representada pelos tamanhos crescentes dos círculos e dos retângulos.

Além do IST, utilizou-se também um roteiro de entrevista, subdividido em duas grandes partes: a primeira composta de grupos de questões sobre as diferentes facetas da vida iniciando pelo trabalho; a segunda solicitava do participante falar sobre a compreensão de questões do IST.

\section{Procedimentos de Coleta de Dados}

Os dados foram coletados em sessões de aplicação coletiva do IST com o máximo de 13 participantes. Cada sessão era introduzida por: (a) apresentação dos aplicadores e exposição dos objetivos, (b) instruções gerais sobre o anonimato dos participantes e a livre deliberação de cada um em responder e (c) instruções específicas sobre a forma de responder ao questionário, as quais incluíam aplicação de três itens como exemplos. Seguia-se, então, a aplicação propriamente dita do IST.

Realizaram-se também entrevistas semi-estruturadas e gravadas com 15 trabalhadores (subamostra) com o intuito de apoiar a análise semântica dos itens do questionário e/ou a interpretação dos fatores. Posteriormente, as entrevistas foram transcritas para possibilitar o trabalho de análise.

\section{Procedimentos de Análise dos Dados}

Todas as respostas dos participantes da amostra ao IST foram registradas na forma de banco de dados do programa de informática - SPSS for Windows (Statistical Package for Social Sciences) - facilitando a aplicação de recursos estatísticos.

Visando ao uso da técnica de análise fatorial, preliminarmente, observou-se que os indicadores de "fatorabilidade" (Tabachnick \& Fidell, 1989) dos dados separados em dois grupos de respostas um, daquelas correspondentes aos atributos valorativos (Escala Verde- EV) e outro, aos atributos descritivos (Escala Azul- EA) - eram adequados ${ }^{4}$.

Para identificação do número de fatores, constatou-se que as estatísticas iniciais da Análise de Componentes Principais, para ambas 
as escalas, indicavam a existência de 19 fatores (Eigenvalues $>1,0$ ). Entretanto, tomando-se por base o exame dos gráficos Scree Plot que associa os Eigenvalues ao número de fatores, recomendava-se a extração de cinco fatores. Ressalta-se que a partir do sexto fator, em ambas as escalas, cada um, separadamente, explica diminutas proporções da variância. A repetição desta análise exploratória, com rotação oblíqua, confirmou a adequação da mesma também para as duas escalas, à medida que havia correlações consideráveis entre os fatores ${ }^{5}$.

Realizadas as análises preliminares, procederam-se as análises fatoriais ${ }^{6}$ com as duas escalas, identificando os fatores primários de cada uma (apresentados na seção seguinte). Como foi aplicada a rotação oblíqua, desenvolveram-se também análises secundárias, as quais consistiram no desenvolvimento subseqüente de análises fatoriais solicitando a identificação de um número de fatores cada vez menor.

\section{Resultados}

\section{A estrutura dos atributos valorativos (Escala V)}

\section{Fatores Primários}

Os fatores primários (Tabela A1) identificados na estrutura dos atributos valorativos são, pois:

- Exigências Sociais ( $\mathrm{a}=$ 0,87; Prop. Da Var. Comp. 61,8\%): Reúne itens que dizem respeito à semelhança e repetição das tarefas e da contribuição ao progresso social do trabalho associado ao uso das capacidades intelectuais, reconhecimento das relações de autoridade e de ocupação. Em outras palavras, pode dizer-se que o fator traduz a atribuição de que o trabalho deve significar responsabilidade social (demandas sociais).

Os itens que versam sobre a repetição das tarefas não têm uma conotação de execução mecânica ou de embrutecimento humano para os participantes da amostra, porque estão associados ao uso do pensamento, como é possível observar na própria composição do fator (Tabela A1). Tal observação é também amparada pela descrição da materialidade do trabalho dos participantes da amostra, pois, em 
ambas categorias ocupacionais, as atividades não são acentuadamente "taylorizadas", no sentido de parcelamento das tarefas em operações, ou acentuadamente mecanizadas, num sentido "fordista": comerciários e trabalhadores da construção habitacional repetem tarefas ou atividades e não operações.

Como o fator também inclui itens que revelam uma exigência de qualidade e a noção de que os resultados do trabalho dignificam a pessoa (itens com pesos mais baixas), então é compreendido que a responsabilidade social traz associada a si dignidade. Ter uma ocupação, responsabilidade social ou responder demandas sociais com o trabalho dignifica a pessoa.

Ilustrando a interpretação deste fator, registra-se que das 15 entrevistas realizadas com os empregados, sete deles responderam a questão - "O que você faz no seu trabalho?" - desenvolvendo imediatamente uma descrição de rotina bem estabelecida, porém não rígida. Entre os trabalhadores das redes de supermercado, tal descrição incluía a referência à extrapolação da função para a qual eram "oficialmente" designados. Falam de uma demanda acentuada, o que justifica o item "Trabalhando sinto-me atarefado" no fator que explica a maior proporção da variância.

Em suma, os itens que apresentam os mais elevados pesos falando da semelhança entre tarefas e da contribuição ao progresso estão aliados às noções de demanda e fim social; por isso, o fator foi denominado de "Exigências Sociais".

- Justiça no Trabalho ( $\mathrm{a}=$ 0,90 e Prop. Var. Comp. $=18,5 \%$ ): Reúne itens que tratam da definição do trabalho como devendo proporcionar proteção ao indivíduo, através da oferta de assistência na forma de segurança física, higiene e conforto no ambiente de trabalho, da garantia dos seus direitos, igualdade de esforços e proporcionalidade entre seu esforço e recompensas, do acolhimento interpessoal tanto pelos colegas como pelas chefias e respeito como pessoa (que opina).

Apesar de claro, do ponto de vista da interpretação, e consistente, do ponto de vista do coeficiente alfa e dos pesos fatoriais dos itens, este fator apresenta uma elevada complexidade quanto à di- 
versidade de idéias que reúne, ou seja, pontua no sentido de que justiça no trabalho é expressa de muitas formas.

Observou-se, nas entrevistas, embora sem questionar diretamente se trabalhar significa justiça, a inclusão de conteúdos com um caráter de reclamação, isto é, que os aspectos que exprimem justiça não ocorrem na realidade. A definição de que deve ocorrer apresenta-se implícita. Corroborando o nível de complexidade deste fator, tais respostas são dispersas entre as várias formas de expressão da justiça. Assim, ocorreram duas referências diretas à exploração, sendo uma associada ao discurso conformista junto com a defesa conjuntural da submissão e outra, à desproporção entre apoio infra-estrutural e cobrança; cinco queixas em torno de problemas com jornada no trabalho; três sobre a alimentação e higiene, sendo uma na construção habitacional; uma referência à falta de expectativa de seu esforço ser reconhecido; uma queixa do caráter formal de alguns direitos que não se tornam realidade e uma queixa da variação das condições de apoio ao trabalho entre as dependência da mesma empresa.

- Esforço Corporal e Desumanização ( $a=0,81$ e Prop. Var. Comp. $=9,1 \%$ ): Reúne itens que definem que o trabalho deve representar esforço corporal (físico), na forma de uma carga (ser pesado), e um ritmo acentuado (concluir com pressa) e ao mesmo tempo desumanização (torna máquina ou animal), discriminação e esgotamento. Em outras palavras, traz a noção de que o trabalho deveria ser mesmo um fardo (um peso), que levaria ao desgaste corporal.

- Realização Pessoal ( $\mathrm{a}=$ 0,79 e Prop. da Var. Comp. $=6,0 \%)$ : Reúne itens que expressam a definição valorativa do trabalho como devendo proporcionar prazer ao indivíduo quanto ao significado dos resultados de trabalho, exigência de raciocínio (desafio), pelo direito a recompensas, autovalorização, interesse pela tarefa e crescimento pessoal. Em outras palavras, o fio condutor que une todos os itens deste fator é o prazer, porém um prazer de múltiplas causas ou fontes.

Entretanto, ao mesmo tempo em que tem uma natureza pessoal, não é caracteristicamente egocêntrico, porque revela uma expectativa de prazer pelos ganhos alheios, já que o item de maior peso é “Trabalhando, penso quanto os outros vão se beneficiar dos resulta- 
dos do meu trabalho". A frase que encabeça o fator, portanto, aponta uma valorização dos resultados gerados pelo trabalho, por trazerem benefícios aos outros.

A interpretação baseada na diversidade do prazer encontra amparo nas entrevistas porque, quando questionados sobre o que satisfaz no trabalho, os entrevistados apresentam uma diferenciação de motivos, nos quais: três falam na identificação com a tarefa, dois pelas oportunidades de participar e opinar, dois por garantir suas despesas básicas, um nas relações interpessoais como conteúdo da tarefa (atendimento ao público), um pela variedade das tarefas (ser atarefado), um pela oportunidade de aprendizagem, um pela oportunidade de crescimento, um por se sentir reconhecido e um pelo relacionamento com os colegas.

- Sobrevivência Pessoal e Familiar ( $\mathrm{a}=0,81$ e Prop. Var. Comp.= 4,6\%): Reúne itens cuja idéia principal é atribuir ao trabalho o papel de garantir o sustento do indivíduo e de seus familiares.

Este fator tem uma conotação fisiológica, além da econômica. As entrevistas realizadas com a mesma amostra revelam que não só o termo sobrevivência, mas também, a frase "O trabalho é a principal força da existência humana”, traduzem a noção de que é preciso trabalhar para estar vivo.

Tal fator também tem uma conotação moral, pois os itens que definem o trabalho como responsabilidade e obrigação geral também apresentam pesos neste fator. Mais secundariamente, inclui aspectos interpessoais, através do item "Trabalhando se faz amigos".

Sobre a interpretação dos fatores, é ainda importante observar que o sinal dos pesos fatoriais (matriz padrão) indica a direção do fator no conjunto da estrutura e não a forma de contribuição do item no fator. Corroborando esta interpretação, observa-se que: 1) na estrutura fatorial apresentada em cada fator os itens assumem todos o mesmo sinal; 2) a distribuição dos escores atribuídos pelos indivíduos aos itens componentes do segundo (Justiça no Trabalho) e quinto fatores (Sobrevivência Pessoal e Familiar) são crescentes (ou seja, há maior concentração dos participantes da amostra quanto maior o escore); e 3) solicitando a apresentação gráfica dos fatores através 
do SSPS, o segundo fator, por exemplo (Figura 1), forma um ângulo obtuso em relação aos demais, de modo que o co-seno do ângulo é necessariamente negativo implicando, por conseqüência, pesos negativos nos itens do fator.

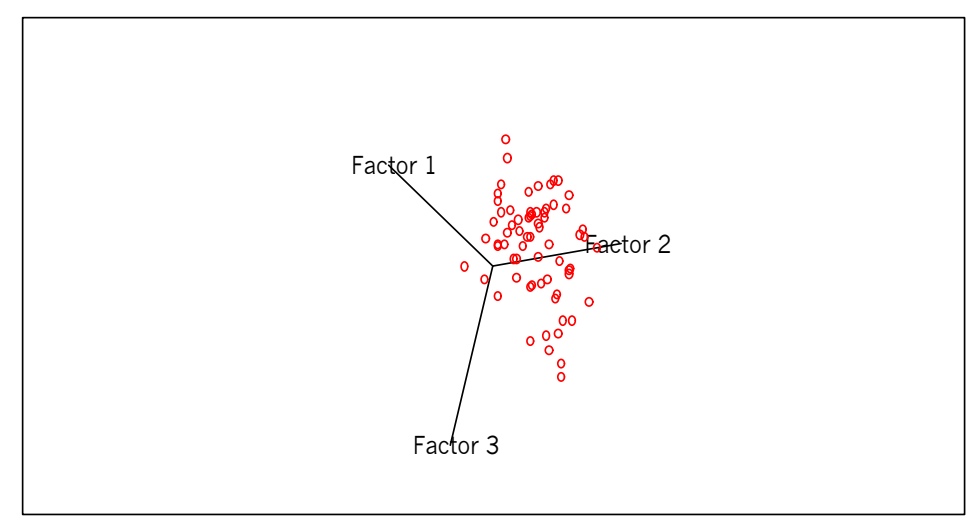

Figura 1: Três primeiros fatores da Escala dos Fatores Valorativos

\section{Fatores Valorativos Secundários}

Numa primeira análise secundária, encontrou-se, então, um fator que reúne os itens do primeiro fator valorativo primário (Exigências Sociais) e o quinto (Sobrevivência), o qual se designou de "Sócio-responsabilidade", mantendo-se os demais fatores da estrutura primária.

Como os pesos fatoriais dos itens daqueles fatores primários reunidos no novo fator Sócio-responsabilidade apresentavam sinais contrários na estrutura primária, o último fator representa a expectativa de compatibilizar as direções, privilegiando as exigências sociais e externas do trabalho, à medida em que, na sua composição, os itens de maiores pesos fatoriais passam a ser: os itens 43 ("O trabalho é a base do progresso de uma sociedade"), 58 ("Trabalhando, sinto-me gente") e 26 ("Reconheço a autoridade dos superiores"). Fortalece, portanto, a noção de que as exigências sociais assumem uma posição 
muito forte no leque de valores do trabalho, o que já estava presente na descrição dos próprios fatores primários, à medida que o fator FV1 ("Exigências Sociais") explica uma maior proporção da variância (61,8\% da variância compartilhada).

Encontrou-se, em seguida, um fator terciário que vem reunir os itens do fator secundário já citado e os itens do fator FV24 ("Realização Pessoal"). Este fator terciário revela a forte associação positiva existente entre os fatores que reúne, estimada na correlação entre os escores nos fatoriais de $r=0,65$. Isto significa dizer que os participantes da amostra não só pensam que o trabalho deve criar oportunidades de exprimir tanto o prazer quanto a responsabilidade social, mas que há uma expectativa de ocorrência de ambas as formas de expressão conjuntamente, de maneira que uma seja dependente da outra.

Em outras palavras, quanto mais se sente prazer no trabalho mais se assumem responsabilidades sociais. Isto vem confirmar o que já se assinalou sobre o prazer pessoal no trabalho, no nível dos valores, não ter um caráter exclusivamente egocêntrico, mas voltado para os outros.

A extração de fatores quaternários faz emergir dois fatores que dividem a totalidade dos itens em dois blocos correlacionados $(r=$ 0,56) e explicando $30,1 \%$ da variância total. O primeiro, designando-se de "Sócio-exigências", reúne os itens dos fatores FV1 ("Exigências Sociais"), FV5 ("Sobrevivência Pessoal e Familiar"), FV3 ("Esforço Corporal e Desumanização") e o item que cedia uma característica altruísta para o fator FV4 ("Realização Pessoal”, item 9 - "Trabalhando, penso quanto os outros vão se beneficiar dos resultados do meu trabalho") e explica 75,4\% da variância compartilhada.

O segundo fator quaternário, designando-se de "Humanização", reúne os itens dos fatores primários de "Justiça no Trabalho" e "Realização Pessoal", excluindo deste último o item 9, de cunho altruísta. Reúne, então, as expectativas de justiça no trabalho com a realização pessoal.

Em outros termos, o primeiro fator quaternário representa a exigência da sociedade e da família em relação a quem trabalha e o segundo a expectativa das condições almejadas pelo trabalhador para que possa atender às primeiras. 
Embora os dois fatores estejam correlacionados positivamente, os pesos fatoriais do segundo fator quaternário (Humanização) são todos negativos sublinhando distintas direções. Quanto mais elevados estes valores para o trabalhador, mais exigem energia em compatibilizá-los. As distintas direções entre os dois conjuntos de valores podem ser vivenciadas de forma conflituosa pelo indivíduo, justamente por serem correlacionadas positivamente e não pelo contrário.

Em suma, como esta análise divide o conjunto de itens em apenas dois fatores, compreende-se que a referida divergência de direção representa a principal fonte de dinamismo (contradição dialética) na estrutura dos valores do trabalho para os participantes da amostra. E, sendo o primeiro fator que explica a maior parte da variância ( $3 / 4$ ), pode se dizer que os fins sociais do trabalho assumem um papel aglutinador muito forte dos seus valores .

\section{A estrutura dos atributos descritivos (Escala A)}

\section{Fatores Primários}

$\mathrm{Na}$ estrutura dos atributos descritivos (Tabela A2), identificaram-se os seguintes fatores primários:

- FD1 - "Êxito e Realização Pessoal" ( $a=0,82$; Prop. Var. Comp= $55,6 \%$ ): Descreve o trabalho a partir de duas idéias principais - crescimento pessoal e desafio mental (intelectual) - expresso nos três itens com os maiores pesos e outros itens com menores pesos. Junto a estas idéias, segue-se a noção de responsabilidade e, mais secundariamente, respeito vivenciado no relacionamento hierárquico, o prazer direto com o conteúdo da tarefa.

- FD2 - "Justiça no Trabalho" ( $\mathrm{a}=0,87$ e Prop. Var. Comp. = 19,8\%): Reúne itens que descrevem o trabalho enquanto representando o respeito que o trabalhador vivencia no ambiente organizacional, na forma de cumprimento das obrigações por parte da organização para com ele, nos cuidados com a higiene, na assistência merecida, na segurança física, no relacionamento interpessoal hierárquico, nos instrumentos de trabalho disponíveis, no aproveitamento de suas opiniões, no conforto, na proporção do seu esforço e 
as recompensas, no reconhecimento deste esforço e na igualdade de exigências.

- FD3 - "Sobrevivência Pessoal e Familiar, Independência Econômica" ( $\mathrm{a}=0,83$; Prop. da Var. Comp. $=6,9 \%)$ : Reúne os itens que expressam, num primeiro plano (maiores cargas), a função social do trabalho em relação à família e às garantias individuais de sobrevivência, recompensas e independência financeira e, no plano imediatamente seguinte, a função social mais ampla (progresso da sociedade) ${ }^{7}$.

- FD5 - "Carga Mental" ( $\mathrm{a}=$ 0,77; Prop. da Var. Comp. = 5,7\%): Descreve o trabalho como representando esforço mental, subordinação hierárquica, repetição, execução e exigência de ritmo.

Observa-se que o fator que está sendo excluído desta análise, devido à baixa consistência (coeficiente Alfa), explica uma pequena parcela da variância compartilhada e reúne poucos itens.

\section{Fatores Descritivos Secundários}

Encontrou-se, então, um fator de segunda ordem que reúne os itens do primeiro ("Êxito e Realização Pessoal") e do quinto fatores primários ("Carga Mental"). Neste, o item de maior peso refere-se à dureza do trabalho, seguido pelo uso do pensamento, execução da tarefa e preenchimento de tempo. As idéias de desafio, de ritmo e de aprendizagem seguem-se mais distantes. E, ainda mais distante, a noção de responsabilidade. $\mathrm{O}$ item 22 , sobre crescimento pessoal, que apresentou o principal peso do primeiro fator primário, passa a apresentar aqui um peso de 0,34 . Representa, portanto, uma contribuição bastante secundária. Daí, conclui-se que a idéia que une os dois fatores é exatamente a dureza, esforço e dedicação ao trabalho. Os demais fatores primários reproduzem-se neste segundo nível de análise.

Encontrou-se, então, um fator de terceira ordem que incorpora ao fator secundário os itens 52 ("Trabalhando, sinto-me como máquina ou animal"), 29 (“Trabalhar exige esforço físico") e 57 (“O trabalho me deixa esgotado") do quarto fator primário, fortalecendo a idéia de dureza do trabalho com o esforço físico; portanto, foi designado de Carga Ocupacional $(\mathrm{a}=0,89)$. Os demais fatores descritivos reproduzem-se neste nível. E os escores no fator terciário FD31 
("Carga Ocupacional") relaciona-se de maneira diretamente proporcional com os escores no fator FD33 ("Êxito e Realização Pessoal") e do fator FD32 ("Justiça no Trabalho"), porém os pesos fatoriais dos itens que compõem o fator FD33 ("Sobrevivência Pessoal e Familiar") são negativos indicando que o fator apresenta uma direção distinta dos demais. É pertinente lembrar que esta posição do fator "Sobrevivência Pessoal e Familiar e Independência Econômica" vem persistindo desde a análise primária.

Encontrou-se, ainda, em uma ordem quaternária, um fator $(\mathrm{a}=$ $0,91)$ que foi designado de "Responsabilidades Recíprocas" que, por sua vez, reúne os itens do fator terciário aos itens do terceiro fator primário. Portanto, representa a compatibilização de aspectos da realidade que têm direções distintas: a percepção de carga ocupacional em relação à sobrevivência pessoal e familiar e independência, onde os principais pesos fatoriais continuam a ser as referentes à dureza e à carga do trabalho.

Observa-se que a análise quaternária separa a totalidade dos itens em dois blocos, os quais são muito desiguais na quantidade de itens. O que também indica que a noção de dureza e/ou carga no trabalho é muito forte quanto ao poder aglutinador.

A referida observação é corroborada pela observação de que, nas entrevistas, as respostas sobre os problemas vividos no trabalho são bastante dispersas em relação ao que elegem como principal; entretanto, 11 dos entrevistados $(\mathrm{n}=15)$ queixaram-se de sobrecarga, embora em várias formas: prorrogação de jornada, ritmo, multiplicidade de tarefas e/ou demandas, dureza associada à natureza da tarefa.

O segundo fator primário mantém-se em todas as análises, de modo que se constitui em um bloco correlacionado positivamente com o primeiro fator quaternário.

\section{Discussão}

A comparação das estruturas fatoriais dos Atributos Valorativos e dos Descritivos

As duas estruturas que emergiram são distintas tanto em seus conteúdos quanto nas suas relações dinâmicas. Enquanto o primeiro 
fator da Escala dos Atributos Valorativos foi designado de Exigências Sociais, porque inclui, entre os principais itens, a função do trabalho para promover o progresso social, e revela as expectativas de que o trabalho representa prazer pessoal, mas prazer associado a fins altruístas (fins sociais), na Escala dos Atributos Descritivos o primeiro fator é o "Êxito e Realização Pessoal", que tem um caráter individualista. Fins sociais amplos só aparecem nesta escala num nível secundário.

Em contrapartida à natureza individualista dos fatores primários na Escala dos Atributos Descritivos, as análises secundárias mostram que a idéia de carga ocupacional é a que mais agrega atributos nesta escala. Isto leva a compreender que a não-observação de um fator consistente na Escala de Atributos Descritivos, correspondente ao que foi designado de "Esforço Físico/Desumanização" na Escala de Atributos Valorativos, não significa que não sejam categorias úteis para a descrição do trabalho concreto. Pelo contrário, revela que não é possível separá-la, porque está fortemente associada à noção de carga ocupacional.

Sumariando, enquanto a função social do trabalho, no nível dos valores, apresenta elevada força aglutinadora, no nível da percepção da realidade, a carga ocupacional ou caráter de dureza do trabalho é que exerce o mesmo papel.

Na estrutura dos Atributos Valorativos, os fatores quaternários dividem o conjunto de itens em dois blocos, com distintas direções, embora mutuamente associados de maneira diretamente proporcional, enquanto que na estrutura dos Atributos Descritivos os fatores quaternários dividem o conjunto de itens em dois blocos associados mutuamente, numa relação diretamente proporcional e de mesma direção. A distinção de sinal dos dois relacionamentos (estatísticos) é compreendida como resultante da natureza também distinta dos fatores.

Assim, o dinamismo da primeira estrutura assinala que os participantes da amostra percebem em suas expectativas que o trabalho assume uma função de atendimento às demandas sociais, como opostas às suas expectativas de que o trabalho lhes proporcione humanização. Compreende-se que, nesta estrutura, a contradição assinalada revela a contradição entre fins coletivistas e individuais. 
Na estrutura dos Atributos Descritivos, ambos os fatores quaternários sintetizam idéias voltadas para o próprio indivíduo, portanto de uma mesma direção.

Além destes aspectos mais gerais, que diferenciam as duas estruturas fatoriais, uma particularidade merece ser assinalada. Usouse a mesma designação ("Justiça no Trabalho") para o segundo fator das duas estruturas. Apesar de reunirem noções bastante semelhantes que justificam a uniformidade de designação, há aspectos qualitativos que os diferenciam. Além de um se referir a um deve ser (valorativo) e outro, ao que é (descritivo), no valorativo o item que tem maior peso fatorial $(-0,81)$ é "Recebo toda assistência que mereço", enquanto que, no fator descritivo, este mesmo item passa a apresentar o quarto peso $(0,64)$. O maior peso fatorial $(0,68)$ neste último fator é atribuído ao item "A empresa cumpre com as obrigações para comigo". O mesmo item enquanto valorativo apresenta o quarto peso do fator. Portanto, embora se compreenda que ambos os fatores representam a idéia de justiça no trabalho, apresentam uma concepção diferenciada da mesma.

Do ponto de vista das semelhanças entre as duas estruturas, sublinha-se que em ambas há predomínio de correlações positivas entre os fatores, revelando que, longe de descrições dicotômicas do significado do trabalho que se esgota nas categorias de significados positivos ou negativos, são caracteristicamente dialéticas, no sentido de que trazem ao mesmo tempo o positivo e o negativo. Assim, a estrutura dos atributos valorativos revela um significado do trabalho que define que este, ao mesmo tempo, deve atender demandas sociais e aspirações humanistas, além de ser desumanizante e levar ao esgotamento. A estrutura dos atributos descritivos, por sua vez, revela um trabalho que propicia êxito pessoal, sobrevivência, assistência etc., mas também, uma carga acentuada.

\section{O apoio da Teoria dos Valores Individuais Básicos}

Quanto à estrutura de atributos de valores do trabalho aqui descrita, considera-se que encontra apoio na Teoria dos Valores Individuais Básicos. A quantidade de fatores valorativos identificados aqui é menor do que os dez tipos de Schwartz (1992 e 1994) e Tamayo e 
Schwartz (1993). Entretanto, é possível observar que os valores (na maioria) que compõem um mesmo fator ou são de um mesmo de tipo de valores ou estão em áreas que se relacionam por adjacência, para Schwartz.

Assim, o fator Exigências Sociais reúne valores dos tipos: Tradição, Conformidade e Universalismo (no tocante aos fins do trabalho de promover o progresso da sociedade).

O segundo fator (FV2, "Justiça no Trabalho") reúne valores do tipo de Segurança mais valores de igualdade que em Schwartz (1992 e 1994) está incluso em Universalismo.

O quarto fator (FV4, "Realização Pessoal") reúne valores que estão nos tipos Realização e Hedonismo. Neste, entretanto, há uma particularidade que importa assinalar, qual seja, inclui um valor que seria classificado como Universalismo ("Trabalhando, penso quanto os outros vão se beneficiar dos resultados do meu trabalho"). Entretanto, esta unidade aqui encontrada entre prazer/realização e valores prosociais não é novidade. Schwartz e Bilsky (1987) haviam assinalado que, em culturas coletivistas, era possível compatibilizar valores de realização com valores pró-sociais.

O quinto fator, por sua vez, (FV5, "Sobrevivência Pessoal e Familiar"), reúne valores que seriam classificados por "Autodireção", embora lhe acrescendo um caráter mais radical, porque não tem apenas uma conotação de independência, mas muito mais de estar vivo.

O terceiro fator (FV3, "Esforço Corporal e Desumanização"), tratando-se de aspecto específico do mundo do trabalho e da realidade local, não pode ser incluído nos tipos de valores humanos da citada linha de pesquisa, distinguindo-se neste ponto dos demais fatores.

Como FV1 ("Exigências Sociais") e FV5 ("Sobrevivência Pessoal e Familiar") apresentam-se em planos distintos ${ }^{8}$, entende-se que os participantes da amostra percebem os interesses da família em direção distinta dos interesses da sociedade e/ou da organização onde trabalham. Tal contradição é análoga à polarização entre "autotranscedência" versus "autopromoção" na Teoria dos Valores Individuais Básicos. 
O posicionamento dos fatores FV2 ("Justiça no Trabalho") e FV4 ("Realização"), também em planos distintos, revelando a dificuldade em compatibilizar a necessidade de justiça com buscar prazer, é análogo à polarização entre "Abertura" e "Conservação".

A formação dos fatores quaternários, por sua vez, (a) no fator "Sócio-Exigências", indicaria a resolução do primeiro conflito ("autotranscedência" x "autopromoção") pela reafirmação do primeiro pólo de forma que justifica ter "Esforço Corporal e Desumanização" como valor; enquanto que (b) no fator "Humanização no Trabalho" indicaria a resolução do conflito ("conservação" x "abertura"), pela reafirmação do primeiro pólo. Entre os dois fatores quaternários, estaria, então, representada a contradição entre valores coletivistas e individualistas.

Portanto, esta analogia corrobora o argumento de Schwartz (1992 e 1994) e Ros \& Schwartz (1995) de que somente a contradição "individualismo" versus "coletivismo" é insuficiente para explicar as relações dinâmicas entre valores. Porém, sugere que esta contradição estaria por trás dos dois eixos da referida teoria, à medida que foi ela que continuou presente na análise quaternária, a qual divide todos os itens em dois grandes blocos.

\section{Da consecução dos objetivos}

Retomando os objetivos apresentadas no início deste artigo, avalia-se o aprofundamento atingido da compreensão sobre a estrutura fatorial dos Atributos Valorativos e Descritivos do Significado do Trabalho e os aperfeiçoamentos promovidos no instrumento de medida, o Inventário do Significado do Trabalho. Compara-se, então, os resultados aqui encontrados com aqueles do estudo anterior:

1. Em ambas as Escalas (EV e EA), o acréscimo das questões permitiu a identificação de um maior número de fatores válidos. Assim, na $\mathrm{EV}$, de quatro fatores consistentes no estudo anterior, passou-se para cinco fatores, e na EA, de dois fatores consistentes e um promissor, passou-se a três consistentes e um promissor.

2. O número maior de fatores implicou uma reordenação (mais refinada) dos itens por fator, repercutindo, principalmente, na definição do primeiro fator de cada escala. 
128 L. de O. Borges

3. Os fatores "Justiça no Trabalho" ( $\mathrm{a}=0,86)$, na EV, e "Respeito" (a $=0,75)$, na EA, do estudo anterior se fortaleceram $(\mathrm{a}=0,90$ e $\mathrm{a}=$ 0,87 ) e mudaram um pouco de natureza, porque o aperfeiçoamento dos itens sobre assistência elevaram os pesos fatoriais destes, passando-se, desta forma, a designar ambos de "Justiça no Trabalho". Ambos continuaram sendo o segundo fator em cada escala, quanto à explicação da variância.

4. Continuou-se a ter um fator inconsistente, na EA, à semelhança do estudo anterior (Borges, 1997). A introdução de itens, especialmente aqueles acerca da carga do trabalho permitiram a reordenação dos demais fatores, bem como, encontrar a explicação para a ocorrência na estrutura secundária dos fatores. Na estrutura fatorial dos atributos valorativos, os itens que compõem o fator "Esforço Corporal/Desumanização" apresentam diferenciação suficiente para constituir um fator à parte, enquanto entre os atributos descritivos estão tão imbricados com o êxito e a realização pessoal, que se torna impossível separá-los.

5. Quanto às estruturas fatoriais em vários níveis (primário, secundários etc.), é necessário sublinhar que as estruturas primárias em ambas as facetas são melhores na capacidade de discriminar vários grupos de idéias. Se, porém, for considerado que a principal idéia articuladora dos itens dos atributos valorativos são as exigências sociais, enquanto para os atributos descritivos são carga e/ou dureza do trabalho, as estruturas fatoriais quaternárias de ambas as facetas espelham melhor a diferença estrutural das duas facetas. Desta forma, tanto as estruturas primárias, quanto as secundárias, são importantes para compor a compreensão de cada uma das facetas.

6. Os itens referentes às normas societais distribuíram-se nos diversos fatores (de ambas escalas), corroborando o que se vem defendendo desde estudos anteriores (Borges, 1997 e 1998), no sentido de que não se constituem em faceta distinta.

\section{Conclusões}

Por tudo que foi apresentado neste artigo, principalmente referindo-se à identificação de fatores interpretáveis, aos coeficientes 
alfas satisfatórios, à diferenciação da estrutura fatorial das duas escalas e o apoio da estrutura dos atributos valorativos na Teoria dos Valores Individuais Básicos, conclui-se que há amparo para a distinção entre atributos valorativos e descritivos, para a interpretação dos fatores e para a confiabilidade e validade do IST como medida das duas facetas do significado do trabalho (atributos valorativos e descritivos).

Quanto aos aspectos metodológicos, a combinação de técnicas quantitativas e qualitativas foi frutífera, ganhando o estudo com a complementariedade das duas. Enquanto o uso de um questionário sistemático permitiu aprofundar a compreensão dos atributos valorativos e descritivos, viabilizando discriminações conceituais mais refinadas, o desenvolvimento de entrevistas paralelas à aplicação dos questionários proporcionou, por sua vez, aprofundar a compreensão qualitativa dos fatores identificados.

Por outro lado, é pertinente chamar atenção do leitor para as limitadas condições de generalização à medida que se trabalhou com uma amostra bastante limitada no que se refere à sua representatividade. Decorrente de tal fato, sugere-se que novos estudos com amostras mais amplas e/ou referentes a outros segmentos dos trabalhadores poderão permitir continuar aprofundando e refinando o conhecimento da estrutura fatorial das duas facetas do Significado do Trabalho, objeto do presente estudo.

Por fim, registra-se que as análise aqui apresentadas não esgotam as possibilidades de exploração dos dados coletados. Ressaltase, portanto, que outras análises podem ser relatadas, abrangendo, por exemplo, comparações entre os diversos segmentos da amostra (trabalhadores da construção civil versus trabalhadores das redes de supermercados, trabalhadores da rede pública de supermercados versus da rede privada etc.), o que não se procedeu aqui, centrandose a atenção nos objetivos aqui propostos.

\section{Referências}

Aktouf, O. (1986). Une visíon interne des rapports de travail: le cas de deux brasseries. Le travail humain. 49 (3), 237-248.

Borges-Andrade, J.; Martins, M. C. F., \& Abbad-OC, G. (1995). Estrutura empirica do significado do trabalho: o caso brasiliense. 
In Sociedade Brasileira de Psicologia (Org.), Resumos de comunicações científicas. XXV Reunião Anual de Psicologia. (p.199). Ribeirão Preto: Autor.

Borges-Andrade, J., \& Nogueira, J. G. A. (1994, outubro). Significado do trabalho: o trabalhador brasiliense comparado com o europeu, o asiático e o norte-americano. Trabalho apresentado na XXIV Reunião Anual de Psicologia da Sociedade Brasileira de Psicologia, Ribeirão Preto, SP.

Borges, L. O. (1996). A representação social do trabalho. Estudos de Psicologia. 1(1), 7-25.

Borges, L. O. (1997). Os atributos do significado do trabalho e sua mensuração. Psicologia: Teoria e Pesquisa, 13 (2), 211-220.

Borges, L. O. (1998). Significado do trabalho e socialização organizacional: um estudo empírico entre trabalhadores da construção habitacional e de redes de supermercados. Tese de Doutorado não-publicada. Universidade de Brasília, Brasília.

Borges, L. O. (no prelo) Os Pressupostos dos Estudos do Significado do Trabalho na Psicologia Social: no caminho do existencialismo. Vivência.

Brief, A. P., \& Nord, W. R. (Org.) (1990). Meaning of occupational work: a collection of essays. Massachusetts/Toronto: Lexington Books.

Codo, W. (1984). Relações de trabalho e transformação social. In S. Lane \& W. Codo (Orgs.), Psicologia Social: o homem em movimento (pp.136-51). São Paulo: Brasiliense.

Codo, W. (1993). Individuo, trabalho e sofrimento: uma abordagem interdisciplinar. Petrópolis: Vozes.

Codo, W. , Sampaio, J. J. C., Hitomi, H., \& Bauer, M. (1995). A síndrome do trabalho vazio em bancários. In W. Codo \& J. J. C. Sampaio (Orgs.), Sofrimento psíquico nas organizações (pp.316329). Petrópolis: Vozes.

Jahoda, M. (1987). Empleo y desempleo: un análisis sociopsicológico. Madrid: Ediciones Morata.

Katzell, R. (1994). Contemporary meta-trends in Industrial and Organizational Psychology. In H. C. Triandis, M. D. Dunnette, \& L. M. Hough (Orgs.). Handbook of Industrial \& Organizational Psychology (vol. 4, pp.1-94). California: Consulting Psychology Press.

Kohn, M. L., \& Schooler, C. (1983). Work and personality. New Jersey: Ablex.

Locke, E. A., \& Taylor, M. S. (1990). Stress, coping, and the meaning of work. In A. Brief \& W. R. Nord (Orgs.), Meaning of 
Occupational Work (pp. 135-170). Massachussets/Toronto: Lexington.

Martin-Baró, I. (1990). ¿Trabajador alegre o trabajador Explotado? La identidad del Salvadoreño. Revista Interamericana de Psicologia, 24 (1), 1-24.

Martin-Baró, I. (1992) Los procesos de socialización. In I. MartinBaró, Acción e Ideología: psicología social desde centroamérica (pp.113-180). El Salvador: UCA Editores.

MOW International Rsearch Team (1987) The Meaning of working. London: Academic Press.

Pérez, A. M. (1996). Los significados sociales en torno al trabajo: um estudo empírico articulando metodologías cuantitativas y cualitativas. Revista Latinoamericana de Psicología, 28, (1), 13-30.

Ros, M. \& Schwartz, S. (1995) Jerarquía de valores en países de la europa occidental: una comparación transcultural. Revista Española de Investigaciones Sociológicas. 69, 69-87.

Ros, M., Schwartz, S. H., \& Surkiss, S. (1999). Basic Individual Values, Work Values, and Meaning of Work. Applied Psychology: An International Review, 48, 49-71..

Salmaso, P., \& Pombeni, L. (1986) Le concept de travail. In W. Doise \& A. Palmonari (Orgs.), L'étude des Representations Sociales (pp.196-205). Paris: Pelachaux \& Nestlé S.A. Neuchâtel.

Sato, L. (1993). A representação social do trabalho penoso. In M. J. Spink (Org.), O conhecimento no cotidiano (pp. 188-211). São Paulo: Brasiliense.

Sato, L. (1995). O conhecimento do trabalhador e a teoria das representações sociais. In W. Codo, W. \& J. J. C. Sampaio (Orgs.), Sofrimento psíquico nas organizações: saúde mental e trabalho (pp. 48-57). Petrópolis: Vozes.

Schwartz, S. H. (1992). Universal in the content and structure of values: theoretical advances and empirical tests in 20 countries. Advances in Experimental Social Psychology, 25, 1-65.

Schwartz, S. H. (1994). Are there universal aspects in the structure and contents of human values? Journal of Social Issues, 50 (4), $19-45$.

Schwartz, S. H., \& Bilsky, W. (1987). Toward a universal psychological structure of human values. Journal of Personality and Social Psychology, 53 (3), 550-562.

Schwartz, S. H., \& Bilsky, W. (1990). Toward a theory of the universal content and structure of values: extensions and cross-cultural replications. Journal of Personality and Social Psychology, $58(5), 878-891$. 
Soares, C. R. V. (1992) Significado do trabalho: um estudo comparativo de categorias ocupacionais. Dissertação de Mestrado nãopublicada. Universidade de Brasília, Brasília.

Tabachnick, B. G., \& Fidell, L. S. (1989). Using multivariate statistics. New York: Harper Collins.

Tamayo, A., \& Schwartz, S. H. (1993). Estrutura motivacional dos valores humanos. Psicologia: Teoria e Pesquisa, 9 (2), 329-348.

Tamayo, A. (1994) Escala Fatorial de Atribuições de Causalidade à Pobreza. Psicologia: Teoria e Pesquisa. 10 (1), 21-29.

\section{Registros e agradecimentos}

O estudo relatado no artigo é parte do desenvolvimento da tese de doutorado, "Significado do Trabalho e Socialização Organizacional: um estudo empírico com trabalhadores da construção habitacional e redes de supermercado".

Registra-se aqui os agradecimentos a todos aqueles que de alguma forma colaboraram no desenvolvimento do estudo e, especialmente, ao orientador da referida tese, o Prof. Dr. Álvaro Tamayo.

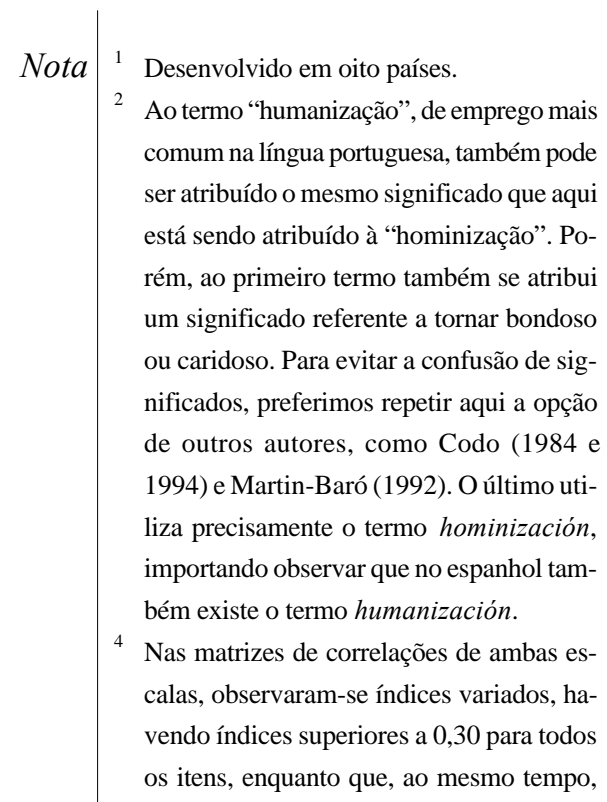


Livia de Oliveira Borges, doutora em Psicologia pelo Instituto de Psicologia da Universidade de Brasília com estágio na Facultad de Ciencias Políticas y Sociología da Universidad Complutense de Madrid, área de concentração em Psicologia Social e do Trabalho, é docente do Departamento de Psicologia da Univer- havia poucos pares de itens com coeficientes de correlação a partir de 0,50 (7 pares na EV e 4 pares na EA). Os demais indicadores de "fatorabilidade" eram também adequados (Determinante da Matriz de Correlação: para a EV < 0,001 e para EA < 0,001; Medida da Adequação da Amostra, de Kaiser-Meyer-Olkin - KMO: para $\mathrm{EV}=0,87$ e para $\mathrm{EA}=0,84$; e o Teste de Esfericidade de Bartlet, para EV =7760,39 e para EA $=6295,94$ ambos com $\mathrm{p}<$ 0,001).

$5 \mathrm{Na}$ EV, os coeficientes da matriz de correlações fatoriais variavam de 0,03 a $0,44 \mathrm{e}$, na EA, de $-0,40$ a 0,22 .

6 Análise Fatorial dos Eixos Principais (PAF), com rotação oblíqua.

7 Ao sinal negativo dos pesos dos itens deste fator, foi dada a mesma interpretação apresentada na Escala V.

8 Na análise fatorial, está expresso por pesos fatoriais de sinais contrários.

Sobre o autor 
134 L. de O. Borges

sidade Federal do Rio Grande do Norte. Endereço para correspondência: R. Prof. Luís Carlos Teixeira,10, Lagoa Nova, Natal, RN. CEP 59.075-130. Telefone: 234-4226.

E-mail: liviab@digi.com.br.

Recebido em 03.07.1998 Revisado em 23.10.1998 Aceito em 22.12.1998 


\section{Apêndice \\ Tabela A1}

Composição e consistência dos fatores primários dos Atributos Valorativos do trabalho - Escala V (Matriz Padrão)

\begin{tabular}{|c|c|c|c|c|c|}
\hline & FV1 & FV2 & FV3 & FV4 & FV5 \\
\hline ALPHAS & 0,87 & 0,90 & 0,81 & 0,79 & 0,81 \\
\hline VARIÂNCIA TOTAL (\%) - 39,8\% & 22,7 & 7,4 & 4,1 & 3,0 & 2,6 \\
\hline VARIÂNCIA COMPARTILHADA (\%) & 61,8 & 18,5 & 9,1 & 6,0 & 4,6 \\
\hline NÚMERO DE ITENS POR FATOR & 14 & 17 & 11 & 11 & 9 \\
\hline 45 Todo dia faço tarefas muito parecidas & 0,61 & & & & \\
\hline $\begin{array}{l}43 \text { O trabalho é a base do progresso de uma } \\
\text { sociedade }\end{array}$ & 0,55 & & & & \\
\hline $\begin{array}{l}47 \text { Trabalhando, estou usando meu } \\
\text { pensamento para fazer as tarefas }\end{array}$ & 0,52 & & & & \\
\hline 26 Reconheço a autoridade dos superiores & 0,51 & & & & \\
\hline 59 Trabalhando, sinto-me atarefado & 0,51 & & & & \\
\hline 58 Trabalhando, sinto-me gente & 0,48 & & & & \\
\hline $\begin{array}{l}46 \text { Trabalhar é estar ocupado, fazendo } \\
\text { alguma coisa }\end{array}$ & 0,47 & & & & \\
\hline 49 Trabalhar é fazer a tarefa. & 0,45 & & & & \\
\hline $28 \mathrm{O}$ trabalho preenche o tempo & 0,43 & & & & \\
\hline $\begin{array}{l}31 \text { Minha tarefa em si exige de mim tentar } \\
\text { fazer melhor }\end{array}$ & 0,39 & & & & \\
\hline $\begin{array}{l}41 \text { Trabalhar bem é o que preciso fazer, para } \\
\text { continuar no meu emprego }\end{array}$ & 0,39 & & & & \\
\hline $\begin{array}{l}11 \text { Sinto que todos os dias estou repetindo as } \\
\text { mesmas coisas }\end{array}$ & 0,37 & & & & \\
\hline $\begin{array}{l}33 \text { O resultado do meu trabalho me torna uma } \\
\text { pessoa digna }\end{array}$ & 0,34 & & & & \\
\hline $\begin{array}{l}44 \text { Trabalho é para ser feito de acordo com o } \\
\text { que dizem os superiores. }\end{array}$ & 0,34 & & & & \\
\hline $\begin{array}{l}50 \text { Trabalho de acordo com minhas } \\
\text { possibilidades }\end{array}$ & 0,33 & & & & \\
\hline 66 Recebo toda assistência que mereço & & $-0,81$ & & & \\
\hline $\begin{array}{l}53 \text { No meu trabalho são adotadas todas as } \\
\text { medidas de segurança física } \\
\text { recomendáveis }\end{array}$ & & $-0,73$ & & & \\
\hline $\begin{array}{l}51 \text { Todos os trabalhadores se esforçam como } \\
\text { eu }\end{array}$ & & $-0,63$ & & & \\
\hline $\begin{array}{l}27 \text { A empresa cumpre com as obrigações para } \\
\text { comigo }\end{array}$ & & $-0,59$ & & & \\
\hline $\begin{array}{l}32 \text { O que ganho no meu trabalho é suficiente } \\
\text { e de acordo com meu esforço }\end{array}$ & & $-0,55$ & & & \\
\hline $\begin{array}{l}65 \text { No meu trabalho tenho as ferramentas } \\
\text { necessárias }\end{array}$ & & $-0,53$ & & & \\
\hline 60 Sou reconhecido pelo que faço & & $-0,52$ & & & \\
\hline 61 Trabalho em ambiente limpo & & $-0,50$ & & & \\
\hline 39 Os colegas de trabalho me querem bem & & $-0,50$ & & & \\
\hline
\end{tabular}


136 L. de O. Borges

\begin{tabular}{|c|c|c|c|c|}
\hline $\begin{array}{l}35 \text { As condições de conforto (higiene, } \\
\text { disponibilidade de materiais, } \\
\text { equipamentos adequados, conveniência } \\
\text { de horário) facilitam a boa execução do } \\
\text { trabalho }\end{array}$ & $-0,49$ & & & \\
\hline $\begin{array}{l}55 \text { Todos que trabalham têm os mesmos } \\
\text { direitos }\end{array}$ & $-0,46$ & & & \\
\hline $\begin{array}{l}16 \text { No meu trabalho são tomadas todos os } \\
\text { cuidados necessários à higiene }\end{array}$ & $-0,42$ & & 0,32 & \\
\hline 21 Os chefes confiam em mim & $-0,40$ & & & \\
\hline $\begin{array}{l}19 \text { Minhas opiniões sobre o trabalho são } \\
\text { levadas em conta }\end{array}$ & $-0,34$ & & & \\
\hline $\begin{array}{l}4 \text { Os chefes sabem como se comunicar com } \\
\text { cada um }\end{array}$ & $-0,33$ & & 0,36 & \\
\hline 63 Quem trabalha está bem de cabeça. & $-0,31$ & & & \\
\hline $\begin{array}{l}24 \text { O trabalho me proporciona as principais } \\
\text { assistências (transporte, educação, saúde, } \\
\text { moradia, aposentadoria etc.) }\end{array}$ & $-0,30$ & & & \\
\hline 12 Trabalhar é pegar no pesado, fazer força & & 0,60 & & \\
\hline $\begin{array}{l}68 \text { Tenho que terminar minhas tarefas com } \\
\text { pressa }\end{array}$ & & 0,56 & & \\
\hline $\begin{array}{l}52 \text { Trabalhando, sinto-me como máquina ou } \\
\text { animal }\end{array}$ & & 0,56 & & \\
\hline 29 Trabalhar exige esforço físico & & 0,56 & & \\
\hline 54 Sou discriminado devido o meu trabalho & & 0,54 & & \\
\hline $\begin{array}{l}64 \text { No trabalho, estão sempre me exigindo } \\
\text { rapidez }\end{array}$ & & 0,54 & & \\
\hline $57 \mathrm{O}$ trabalho me deixa esgotado & & 0,47 & & \\
\hline 56 Esforço-me muito e ganho pouco & & 0,41 & & \\
\hline $\begin{array}{l}30 \text { O trabalho é duro, porque exige muito } \\
\text { esforço, dedicação e luta }\end{array}$ & & 0,38 & & \\
\hline $\begin{array}{l}48 \text { O trabalho é corrido, quando se trabalha } \\
\text { também em casa }\end{array}$ & & 0,36 & & \\
\hline $\begin{array}{l}9 \text { Trabalhando, penso quanto os outros vão } \\
\text { se beneficiar dos resultados do meu } \\
\text { trabalho }\end{array}$ & & & 0,46 & \\
\hline 13 Trabalhar exige da cabeça, do pensamento & & & 0,45 & \\
\hline $\begin{array}{l}10 \text { Se trabalho, tenho direito a um retorno } \\
\text { merecido }\end{array}$ & & & 0,43 & \\
\hline $\begin{array}{l}15 \text { No meu trabalho sinto ser tratado como } \\
\text { pessoa respeitada }\end{array}$ & & & 0,42 & \\
\hline $\begin{array}{l}3 \text { As pessoas sabem quanto é importante o } \\
\text { meu trabalho }\end{array}$ & & & 0,37 & \\
\hline 1 É um prazer realizar minhas tarefas & & & 0,34 & \\
\hline $\begin{array}{l}22 \mathrm{O} \text { trabalho é um meio de crescimento } \\
\text { pessoal na vida }\end{array}$ & & & 0,31 & \\
\hline $\begin{array}{l}14 \text { Tenho que pensar e me esforçar para } \\
\text { conseguir fazer o trabalho }\end{array}$ & & & 0,31 & \\
\hline 50 meu trabalho é o meu sustento & & & & $-0,56$ \\
\hline 40 O trabalho é minha sobrevivência & & & & $-0,53$ \\
\hline $\begin{array}{l}42 \text { Trabalho para ter assistência para mim e } \\
\text { para minha família }\end{array}$ & & & & $-0,50$ \\
\hline
\end{tabular}




\begin{tabular}{|c|l|l|l|l|l|}
\hline $\begin{array}{c}25 \text { Trabalho é responsabilidade, porque quem } \\
\text { trabalha enfrenta os problemas daquele } \\
\text { trabalho }\end{array}$ & & & & 0,33 & $-0,45$ \\
\hline $\begin{array}{c}34 \text { O trabalho é a principal força da } \\
\text { existência humana }\end{array}$ & & & & & $-0,44$ \\
\hline 67 Trabalhando, exercitamos o corpo & & & & & $-0,43$ \\
\hline $\begin{array}{c}37 \text { Eu assumo as conseqüências do que } \\
\text { decido sobre meu trabalho }\end{array}$ & & & & & $-0,37$ \\
\hline 8 Trabalhar é obrigação de todas as pessoas & & & & & $-0,34$ \\
\hline 20 Trabalhando, se faz amigos & & & & & $-0,32$ \\
\hline
\end{tabular}

Tabela A2

Composição e consistência dos fatores primários dos Atributos Descritivos do trabalho - Escala D

\begin{tabular}{|c|c|c|c|c|c|}
\hline & FD1 & FD2 & FD3 & FD4 & FD5 \\
\hline ALPHAS & 0,82 & 0,87 & 0,83 & 0,67 & 0,77 \\
\hline VARIÂNCIA TOTAL & 18,5 & 6,6 & 4,0 & 2,3 & 1,9 \\
\hline VARIÂNCIA COMPARTILHADA (\%) & 55,6 & 19,8 & 12,0 & 6,9 & 5,7 \\
\hline NÚMERO DE ITENS POR FATOR & 16 & 17 & 12 & 07 & 11 \\
\hline $\begin{array}{l}22 \text { O trabalho é um meio de crescimento } \\
\text { pessoal na vida }\end{array}$ & 0,49 & & & & \\
\hline $\begin{array}{l}14 \text { Tenho que pensar e me esforçar para } \\
\text { conseguir fazer o trabalho }\end{array}$ & 0,48 & & & & \\
\hline $\begin{array}{l}31 \text { Minha tarefa em si exige de mim } \\
\text { tentar fazer melhor }\end{array}$ & 0,47 & & & & \\
\hline $\begin{array}{l}25 \text { Trabalho é responsabilidade, porque } \\
\text { quem trabalha enfrenta os problemas } \\
\text { daquele trabalho }\end{array}$ & 0,40 & & & & \\
\hline $\begin{array}{l}37 \text { Eu assumo as conseqüências do que } \\
\text { decido sobre meu trabalho }\end{array}$ & 0,44 & & & & \\
\hline $28 \mathrm{O}$ trabalho preenche o tempo & 0,42 & & & & 0,31 \\
\hline $\begin{array}{l}36 \text { Fazendo minhas tarefas, estou sempre } \\
\text { aprendendo alguma coisa nova }\end{array}$ & 0,39 & & & & \\
\hline $\begin{array}{l}30 \text { O trabalho é duro, porque exige muito } \\
\text { esforço, dedicação e luta }\end{array}$ & 0,37 & & & 0,33 & \\
\hline 21 Os chefes confiam em mim & 0,36 & 0,39 & & & \\
\hline $\begin{array}{l}51 \text { Todos os trabalhadores se esforçam } \\
\text { como eu }\end{array}$ & $-0,36$ & 0,39 & & 0,34 & \\
\hline $\begin{array}{l}23 \text { Trabalhando, sou eu quem decido o } \\
\text { que compro para mim }\end{array}$ & 0,35 & & & & \\
\hline 1 É um prazer realizar minhas tarefas & 0,32 & 0,32 & & & \\
\hline $\begin{array}{l}13 \text { Trabalhar exige da cabeça, do } \\
\text { pensamento }\end{array}$ & 0,32 & & & & \\
\hline 58 Trabalhando, sinto-me gente & 0,32 & & & & \\
\hline 18 Eu gosto de ver minhas tarefas prontas & 0,31 & & & & \\
\hline $\begin{array}{l}2 \text { Trabalhando, tenho oportunidades de } \\
\text { estar sempre mais profissionalizado }\end{array}$ & 0,30 & & & & \\
\hline
\end{tabular}


138 L. de O. Borges

\begin{tabular}{|c|c|c|c|c|}
\hline $\begin{array}{l}27 \text { A empresa cumpre com as obrigações } \\
\text { para comigo }\end{array}$ & 0,68 & & & \\
\hline 61 Trabalho em ambiente limpo & 0,66 & & & 0,32 \\
\hline $\begin{array}{l}16 \text { No meu trabalho são tomados todos os } \\
\text { cuidados necessários à higiene }\end{array}$ & 0,65 & & & \\
\hline 66 Recebo toda assistência que mereço & 0,64 & & & \\
\hline $\begin{array}{l}53 \text { No meu trabalho são adotadas todas as } \\
\text { medidas de segurança física } \\
\text { recomendáveis }\end{array}$ & 0,61 & & & \\
\hline $\begin{array}{l}4 \text { Os chefes sabem como se comunicar } \\
\text { com cada um }\end{array}$ & 0,59 & & & \\
\hline $\begin{array}{l}65 \text { No meu trabalho tenho as ferramentas } \\
\text { necessárias }\end{array}$ & 0,56 & & & \\
\hline $\begin{array}{l}15 \text { No meu trabalho sinto ser tratado } \\
\text { como pessoa respeitada }\end{array}$ & 0,54 & & & \\
\hline $\begin{array}{l}19 \text { Minhas opiniões sobre o trabalho são } \\
\text { levadas em conta }\end{array}$ & 0,50 & & & \\
\hline $\begin{array}{l}35 \text { As condições de conforto (higiene, } \\
\text { disponibilidade de materiais, } \\
\text { equipamentos adequados, } \\
\text { conveniência de horário) facilitam a } \\
\text { boa execução do trabalho }\end{array}$ & 0,49 & & & \\
\hline $\begin{array}{l}32 \text { O que ganho no meu trabalho é } \\
\text { suficiente e de acordo com meu } \\
\text { esforço }\end{array}$ & 0,48 & & & \\
\hline 60 Sou reconhecido pelo que faço & 0,47 & & & \\
\hline $\begin{array}{l}3 \text { As pessoas sabem quanto é importante } \\
\text { o meu trabalho }\end{array}$ & 0,39 & & & \\
\hline $\begin{array}{l}55 \text { Todos que trabalham têm os mesmos } \\
\text { direitos }\end{array}$ & 0,30 & $-0,43$ & & \\
\hline $\begin{array}{l}42 \text { Trabalho para ter assistência para mim } \\
\text { e para minha família }\end{array}$ & & $-0,69$ & & \\
\hline 40 O trabalho é minha sobrevivência & & $-0,68$ & & \\
\hline 7 Ter um emprego é uma garantia & & $-0,60$ & & \\
\hline $\begin{array}{l}10 \text { Se trabalho, tenho direito a um retorno } \\
\text { merecido }\end{array}$ & & $-0,56$ & & \\
\hline $\begin{array}{l}6 \text { Trabalhando, sou independente porque } \\
\text { assumo minhas despesas }\end{array}$ & & $-0,51$ & & \\
\hline $\begin{array}{l}43 \mathrm{O} \text { trabalho é a base do progresso de } \\
\text { uma sociedade }\end{array}$ & & $-0,52$ & & \\
\hline 50 meu trabalho é o meu sustento & & $-0,49$ & & \\
\hline $\begin{array}{l}62 \text { Mereço ganhar mais pelo meu } \\
\text { trablho }\end{array}$ & & $-0,44$ & & \\
\hline 63 Quem trabalha está bem de cabeça & & -044 & & \\
\hline $\begin{array}{l}8 \text { Trabalhar é obrigação de todas as } \\
\text { pessoas }\end{array}$ & & $-0,42$ & & \\
\hline 67 Trabalhando, exercitamos o corpo & & $-0,30$ & & \\
\hline 29 Trabalhar exige esforço físico & & & 0,62 & \\
\hline $\begin{array}{l}52 \text { Trabalhando, sinto-me como máquina } \\
\text { ou animal }\end{array}$ & & & 0,61 & \\
\hline $\begin{array}{l}12 \text { Trabalhar é pegar no pesado, fazer } \\
\text { força }\end{array}$ & & & 0,52 & \\
\hline
\end{tabular}




\begin{tabular}{|l|l|l|l|l|l|}
\hline $\begin{array}{c}\text { 68 Tenho que terminar minhas tarefas } \\
\text { com pressa }\end{array}$ & & & & 0,48 & \\
\hline 57 O trabalho me deixa esgotado & & & & 0,43 & \\
\hline $\begin{array}{c}\text { 47 Trabalhando, estou usando meu } \\
\text { pensamento para fazer as tarefas }\end{array}$ & & & & & 0,49 \\
\hline $\begin{array}{c}\text { 44 Trabalho é para ser feito de acordo } \\
\text { com o que dizem os superiores }\end{array}$ & & & & & 0,48 \\
\hline 45 Todo dia faço tarefas muito parecidas & & & & & 0,46 \\
\hline 49 Trabalhar é fazer a tarefa & & & & & 0,44 \\
\hline 59 Trabalhando, sinto-me atarefado & & & & & 0,43 \\
\hline $\begin{array}{c}\text { 48 O trabalho é corrido, quando se } \\
\text { trabalha também em casa }\end{array}$ & & & & 0,37 \\
\hline $\begin{array}{c}\text { 46 Trabalhar é estar ocupado, fazendo } \\
\text { alguma coisa }\end{array}$ & & & & & 0,36 \\
\hline $\begin{array}{c}\text { 11 Sinto que todos os dias estou } \\
\text { repetindo as mesmas coisas }\end{array}$ & & & & & 0,35 \\
\hline $\begin{array}{c}\text { 64 No trabalho, estão sempre me } \\
\text { exigindo rapidez }\end{array}$ & & & & 0,35 \\
\hline
\end{tabular}

